\title{
Basic Design of Bearingless Switched Reluctance Motor with Hybrid Stator poles
}

\author{
Huijun Wang *, Jianfeng Liu **, and Jin-Woo Ahn ***
}

\begin{abstract}
In this paper, a novel bearingless switched reluctance motor (BLSRM) with hybrid stator poles is proposed. The structure and operating principle are presented. In order to describe the design methodology clearly, analytical torque and radial force models are established. Further, basic design procedure is described. The numbers of phases and poles have important influence on the selection of structure. These effects, along with sizing of machine envelope and internal dimensions, make the machine design an insight-intensive effort. Effect of pole arcs and air-gap length on the production of torque and radial force are analyzed in detail. Mechanical design factors such as hoop stress and first critical speed are also considered. Based on the above analysis, the characteristics of the proposed BLSRM are analyzed. A prototype motor is designed and manufactured. The validity of the proposed structure is verified by the experimental results.
\end{abstract}

Keywords: Design, Bearingless switched reluctance motor, Hybrid Stator

\section{Introduction}

Switched reluctance motors (SRM) have superior performance under special environments, because of inherent advantages due to their characteristics such as fault tolerance, robustness, low cost and possible operation in applications of high temperature or in intense temperature variations. Moreover, an SRM has good features, as it is a bearingless motor, which is characterized by integration of an electrical motor and magnetic bearing. Generally, a significant amount of magnetic attraction force is generated in radial directions. This is because an SRM has a short airgap length in order to produce rotational reluctance torque effectively. It is quite possible to take advantage of this inherent large magnetic attraction force to suspend the rotor shaft.

Recently, several different structures of bearingless switched reluctance motors (BLSRM) have been proposed. However, there are many disadvantages: the operating point has to be selected as a compromise between torque and radial force and regions of generating torque and radial force cannot be fully utilized [1], a high number of switches

\footnotetext{
* School of Instrumentation Science and Opto-electronics Engineering, Beihang University, China. (huijun024@gmail.com)

** School of Instrumentation Science and Opto-electronics Engineering, Beihang University, China.(ljfbuaa@163.com)

*** Dept. of Mechatronics Engineering, Kyungsung University, Busan, Korea . (jwahn@ks.ac.kr)

Received 29 July 2012 ; Accepted 8 August 2012
}

and high cost, a difficulty in avoiding the negative torque that restricts an increase of rotational speed [2], the critical speed of the rotor is reduced due to the increasing of axial length [3]. Therefore, a novel BLSRM structure is proposed in this paper. This new BLSRM has two types of stator poles. One is a torque pole, the other is a suspending force pole. Thus, suspending force and torque will be independently controlled by corresponding stator poles.

This paper is organized as follows. Section II delineates the configuration of the motor and operating principle of radial force. Section 3 describes the analytical torque and radial force model of the BLSRM. Section 4 includes the mechanical and electromagnetic design such as critical speed, and parameters selection. Section 5 contains the basic sizing of the envelope and internal dimensions. Section 6 shows the validity verification by the experimental results.

\section{Configuration of Motor and Principle of Radial Force Production}

Fig. 1(a) shows the structures of the proposed BLSRM. In Fig. 1(a), differing from conventional structure, two types of stator poles are included on the stator. One is a torque pole such as $A_{1}, A_{2}, B_{1}$ and $B_{2}$, which mainly produce rotational torque. The other is a radial force pole such as $\mathrm{P}_{\mathrm{x} 1}, \mathrm{P}_{\mathrm{x} 2}, \mathrm{P}_{\mathrm{x} 3}$ and $\mathrm{P}_{\mathrm{x} 4}$, which mainly generate radial force to suspend rotor and shaft. At the same pole $A_{2}$ are 
connected in series to construct torque winding $\mathrm{A}$, and windings on pole $\mathrm{B}_{1}$ and pole $\mathrm{B}_{2}$ are connected in series to construct torque winding $\mathrm{B}$. windings on poles $\mathrm{P}_{\mathrm{x} 1}, \mathrm{P}_{\mathrm{x} 2}, \mathrm{P}_{\mathrm{x} 3}$ and $\mathrm{P}_{\mathrm{x} 4}$ are independently controlled to construct four radial force windings $\mathrm{P} 1, \mathrm{P} 2, \mathrm{P} 3$ and $\mathrm{P} 4$ in $\mathrm{x}$ and $\mathrm{y}$ directions.

Fig. 1(b) shows the control principle of suspending force. From this figure, when the rotor has eccentric displacement in a positive $y$-direction, only current $i_{2}$ will be turned on and the other radial force winding $\mathrm{P}_{\mathrm{x} 1}, \mathrm{P}_{\mathrm{x} 2}$ and $\mathrm{P}_{\mathrm{x} 3}$ are turned off. Accordingly radial force in negative $y$-direction is generated. Current $i_{2}$ can be regulated until the rotor is in balanced position. Using same method, if the rotor has an eccentric displacement in the positive $\mathrm{x}$-direction at the same time, only winding $\mathrm{P}_{\mathrm{x} 3}$ needs to be turned on and current $i_{3}$ is regulated to make the rotor return to its zero eccentric position.

\section{Analytical Torque and Radial Force Model}

Fig. 2 shows the one stator pole and one rotor pole of a general SRM. The flux passes through the overlap area as well as the non-overlap area due to the fringing effect. The inductance can be expressed as [4]:
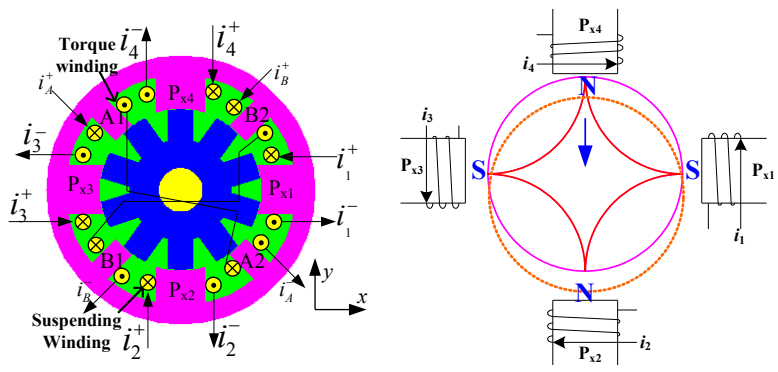

(a) Proposed BLSRM (b) Suspending control principle

Fig. 1. Structure and control principle of proposed BLSRM

$$
L=\frac{\mu_{0} N^{2} L_{s} R_{R} \theta_{0}}{2 g}+N^{2} K_{f} \theta_{u 0}
$$

in which, $\mu_{0}$ is the permeability of the air, $K_{f}$ is a constant for the fringing inductance, $N$ is the number of coil turns, $L_{s t k}$ is the motor stacking length., $R$ is the rotor radius, $\mathrm{g}$ is the air gap length, $\theta_{0}$ and $\theta_{\mathrm{u} 0}$ are the overlapping and the non-overlapping angles, respectively. The radial force $F$ and torque $T$ in this pole can be explained as:

$$
F=\frac{1}{2} i^{2} \frac{\mathrm{d} L}{\mathrm{~d} x}
$$

time, pole arc of radial force is one pole pitch of rotor for producing of continuous radial force. Windings on the pole

A1 and

$$
T=\frac{1}{2} i^{2} \frac{\mathrm{d} L}{\mathrm{~d} \theta}
$$

However, in the proposed structure, the pole arc of radial force tooth is one pole pitch of rotor. At any time the overlap area between the stator and rotor is a constant. The value is equal to the pole arc of the rotor. Therefore, the radial force can be written as follows:

$$
F=\frac{\mu_{0} N^{2} i^{2} L_{s t k} R \beta_{r}}{2 g^{2}}=K_{F} i^{2}
$$

where $K_{F}=\left(\mu_{0} N^{2} L_{\text {stk }} R \beta_{\mathrm{r}}\right) /\left(2 g^{2}\right)$. The above equation shows that the amplitude of the suspending force is approximately proportional to the square of the excitation current in the radial force winding. As well, it is inversely proportional to the square of the air-gap length. However, it is independent of the rotor position. This is one of the advantageous features different from former BLSRM structures.

According to (4), radial force in $\mathrm{x}$ and $\mathrm{y}$ directions can be explained as (5) and (6):

$$
\begin{aligned}
& F_{x}=K_{F}\left(i_{1}^{2}+i_{3}^{2}\right) \\
& F_{y}=K_{F}\left(i_{2}^{2}+i_{4}^{2}\right)
\end{aligned}
$$

The net torque produced by the torque windings can be explained as (7):

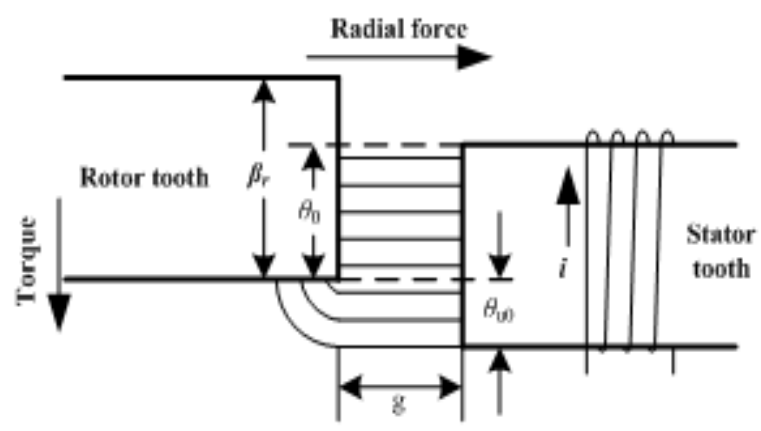

Fig. 2. Magnetic paths between stator and rotor

$$
T=\frac{1}{2}\left(i_{A}^{2}+i_{B}^{2}\right) \frac{d L}{d \theta}
$$

As shown in (7), rotational torque is only dependent on 
the currents in the torque winding. The reason for this is that the variation ratio of radial force winding inductance is very small due to the constant the overlap area. Accordingly, the torque is very small and can be ignored.

\section{Design Methodology of BLSRM}

\subsection{Design Steps}

Fig. 3 shows a comprehensive flowchart describing the design steps. These steps include the initial selection of the BLSRM structure, parameters and related design coefficients. The design specifications mainly include radial force and rated torque. The parameters $B_{\max }, A_{\mathrm{e}}$ and $J$ are the major contributions to the envelope sizing and temperature rise of the BLSRM. In the design, configuration, parameters and design coefficients are modified within their limits to obtain a satisfactory "output checklist" for the design. After that, characteristic curves such as torque and radial force with respect to position and current. In Fig. 3, $D_{\text {ro }}$ and $D_{\text {so }}$ are the outer diameters of the rotor and stator, respectively. $D_{\mathrm{si}}$ is the inner diameter of stator. $t_{\mathrm{st}}$ and $t_{\mathrm{sf}}$ are width of the torque pole and radial force pole on the stator. $t_{\mathrm{r}}$ is pole width of the rotor tooth. $L_{\mathrm{s}}$ and $L_{f}$ are the inductance of the torque winding and radial force winding, respectively. $\beta_{\mathrm{st}}$ and $\beta_{\mathrm{r}}$ are the pole arc of the torque winding tooth and rotor. $N_{s}$ and $N_{r}$ are the pole numbers of the stator and rotor. $W_{s t}$ is the turn number of the torque phase winding and $W_{s f}$ is the turn number of the radial force winding.

\subsection{Output Equation}

The output equation relates to the bore diameter, length, speed and magnetic and electric loadings to the output of a machine. In general, conventional machines are designed starting from the output equation. The flux linkage-current relationship for a flat-topped phase current is shown in Fig. 4. The shaped area SOAB denotes the output mechanical energy. The reluctance torque by phase winding in one period can be written in (8):

$$
T_{p h}=\frac{\Delta W}{\Delta \theta}
$$

where $\Delta \theta=(2 \pi) / \mathrm{Nr}, \mathrm{Nr}$ is pole number of rotor. $\Delta \mathrm{W}=\mathrm{SOAB}$. Thus, phase torque can be explained as follows [5]:

$$
\begin{aligned}
T_{p h} & =k_{e} N_{r} \frac{\psi_{m} i_{m}}{2 \pi} \\
k_{e} & =1-k_{s}-k_{\psi}
\end{aligned}
$$

in which ke is the coefficient of energy conversion, ks is the saturation coefficient and $\mathrm{k} \Psi$ is the ratio of maximum flux linkage to minimum flux linkage.

When neglecting the fringing effect, maximum flux linkage can be explained as (11)

$$
\psi_{m}=B_{\delta} L_{s t k} D_{s i} k_{u} \pi^{2} \frac{W_{s t}}{2 N_{r}}
$$

where $\mathrm{B} \delta$ is the magnetic density of the air-gap, ku represents the minimum pole arcs of the stator and rotor. Combining electric loading Ac and current density J, output equation can be obtained as follows:

$$
\frac{D_{s i}^{2} L_{s t k} n}{P}=\frac{120}{\pi^{2} m k_{u} k_{e} B_{\delta} A_{c}}
$$

From (12), the main dimensions are dependent on speed, electric loading and magnetic loading. A higher speed requires smaller dimensions with the same $\mathrm{Ac}, \mathrm{B} \delta$ and power. Different axial lengths can be used with different powered motors with the given speed and Dsi。

\section{Parameters Selection of BLSRM}

\subsection{Selection of Pole Number}

In the proposed BLSRM, four radial force stator poles are essential to generate suspending force in the four directions. At the same time, considering the symmetry of the structure and output torque, the torque pole number needs to be not less than four. Therefore, the sum of the stator poles should be eight at least.

As for the selection of the rotor pole number, it is restricted by following conditions:

1. The pole number of the rotor should be even. Two stator poles in the diameter direction belong to the same phase. This requires that corresponding rotor poles have same relative positions to the stator poles, respectively.

2. Rotor poles should match with number of stator poles. This requires that the SRM has the capability of continuous output torque. The general combination of pole numbers for stator and rotor is shown in Table I [5]. 
Table 1. General Combination of Pole Number

\begin{tabular}{|c|c|c|c|}
\hline$q$ & $N_{s}$ & \multicolumn{2}{|c|}{$N_{r}$} \\
\hline 3 & 6 & 4 & 8 \\
\hline 4 & 8 & 6 & 10 \\
\hline 5 & 10 & 8 & 12 \\
\hline
\end{tabular}

in Table 1, $q$ is the phase number, $N_{s}$ is the pole number of the stator and $N_{r}$ is the pole number of the rotor.

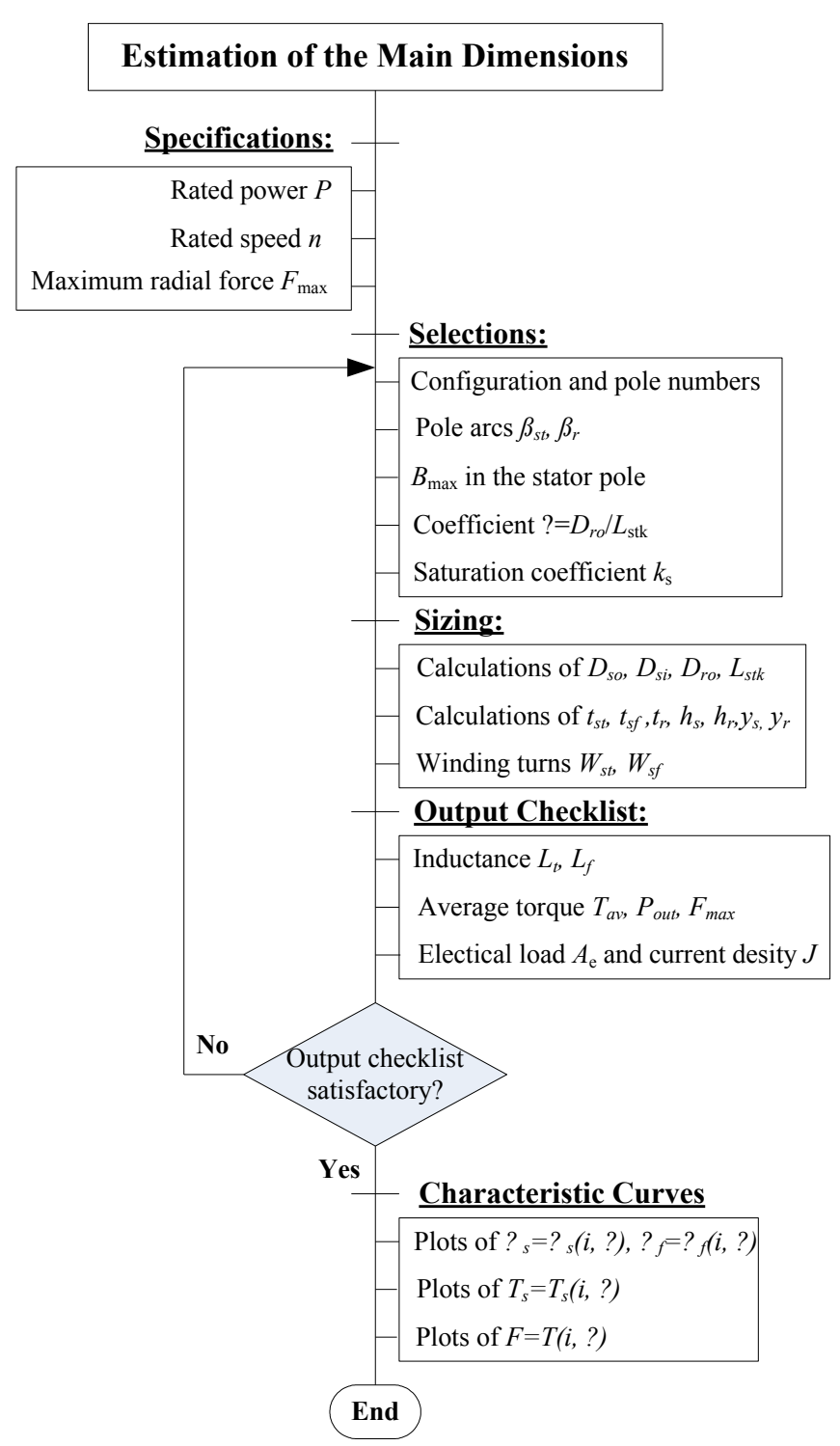

Fig. 3. Flowchart of the overall design of BLSRM

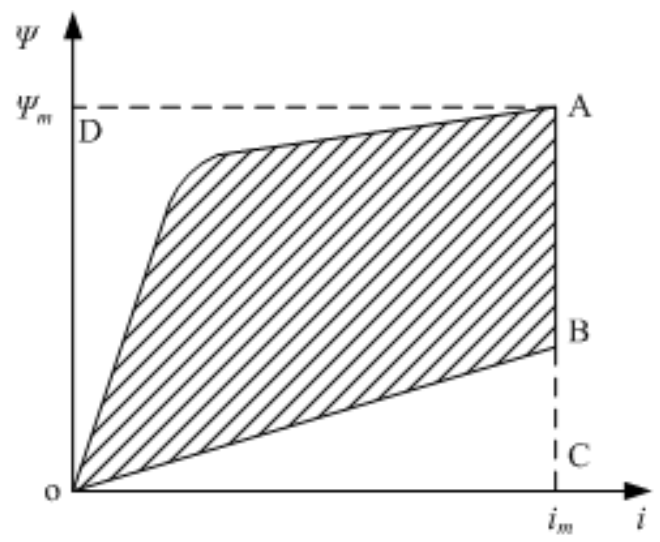

Fig. 4. Relation of flux linkage and current

Further, the relationship between the switching frequency and the rotational speed is shown in (13):

$$
f=q N_{r} n / 60
$$

In (13), $f$ is the switching frequency, $n$ is the speed in rpm. From (13), the switching frequency increases with the phase number, the pole number rotor and speed. Due to high speed application of the BLSRM, phase and pole number of the rotor should be reduced to minimize the switching frequency. So, the pole number of the stator is selected to be eight, the pole number of the rotor will be chosen to be six or ten.

\subsection{Selection of Pole Arc}

The pole arcs of the stator and rotor are important variables in the BLSRM design. Guidelines for their selection are presented in this section.

According to the proposed structure as shown in Fig.5, the pole arc of radial force $\beta_{s f}$ and rotor pole pitch $\tau_{r}$ satisfy following equation:

$$
\beta_{s f}=\tau_{r}=2 \pi / N_{r}
$$

When the pole numbers are decided, pole arc width of radial force is fixed. This means remaining space for installing stator windings is fixed. Therefore, from this point of view, the pole number of the rotor tends to be higher. For example, with the 8 stator poles, the possible case for the rotor pole number is 6 or 10 . However, the rotor with 10 poles is the preferred selection based on the above conclusion. 


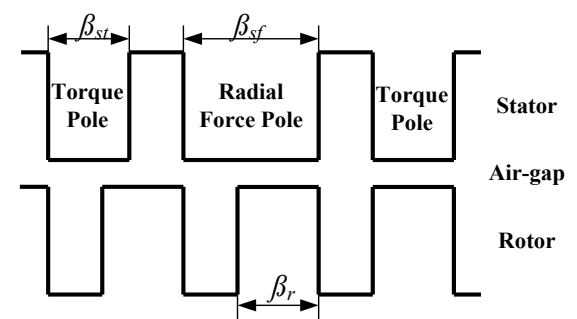

Fig. 5. Simplified structure of proposed BLSRM

Another important aspect is the influence of selection for pole arcs on performance parameters such as radial force, and torque. Firstly, considering pole arcs of torque and rotor have following restricted relations [5]:

$$
\left.\begin{array}{c}
\beta_{s t}+\beta_{r} \leq 2 \pi / N_{r} \\
\beta_{s t} \leq \beta_{r} \\
\beta_{s} \geq 2 \pi /\left(q N_{r}\right)
\end{array}\right\}
$$

The above relations can be reflected by a triangle as shown in Fig. 6. Point A means minimum pole-arc values of the stator and rotor. Point $\mathrm{B}$ means the motor has maximum space for winding. At point $\mathrm{C}$ the motor has no space for winding. Practically, point $\mathrm{C}$ is physically nonsensical. At the same time, the triangle is divided into two parts by line $\mathrm{AD}$. One is the triangle $\mathrm{ADC}$, in which $\beta_{s t}$ is larger than $\beta_{r}$. The other is the triangle $\mathrm{ADB}$, where $\beta_{s t}$ is smaller than $\beta_{r}$. According to (14), selection of $\beta_{s t}$ and $\beta_{r}$ is in the triangle ADB including the boundary [6].

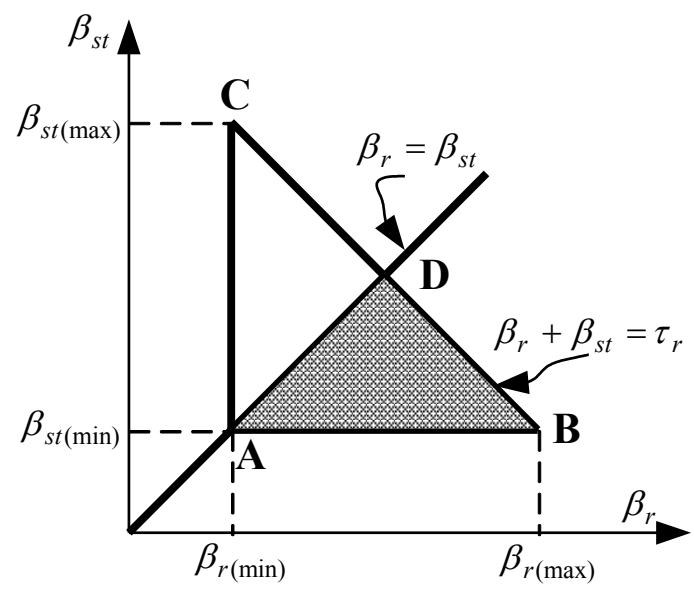

Fig. 6. Relation of pole arcs of torque pole and rotor

Inductances such as aligned inductance, unaligned inductance are important. They not only determine the torque value, but also influence the time of excitation current magnetizing and demagnetizing. Therefore, their sensitivities to the ratio of the rotor to stator torque pole arc as a function of various stator pole enclosures are shown in Fig. 7. Further, the sensitivity as a function of various rotor pole enclosures is shown in Fig. 8. The range of the interest for the ratio of the rotor to stator pole arc is 1 to 2 . In this region the aligned inductance $L_{a}$ is insensitive to the rotor pole enclosure factor. While unaligned, inductance $L_{u}$ changes a little with the increasing of the rotor pole enclosure. The value gradually increases. The variation of the stator pole enclosure is very significant in the same region of interest. With the decreasing of the stator pole enclosure, aligned and unaligned inductances also gradually decrease. From these observations, it can be recommended that the rotor to the stator torque pole ratio should be confined to 1 to 1.3 , with only a variation of $10 \%$ in the ratio of aligned inductance to unaligned inductance.

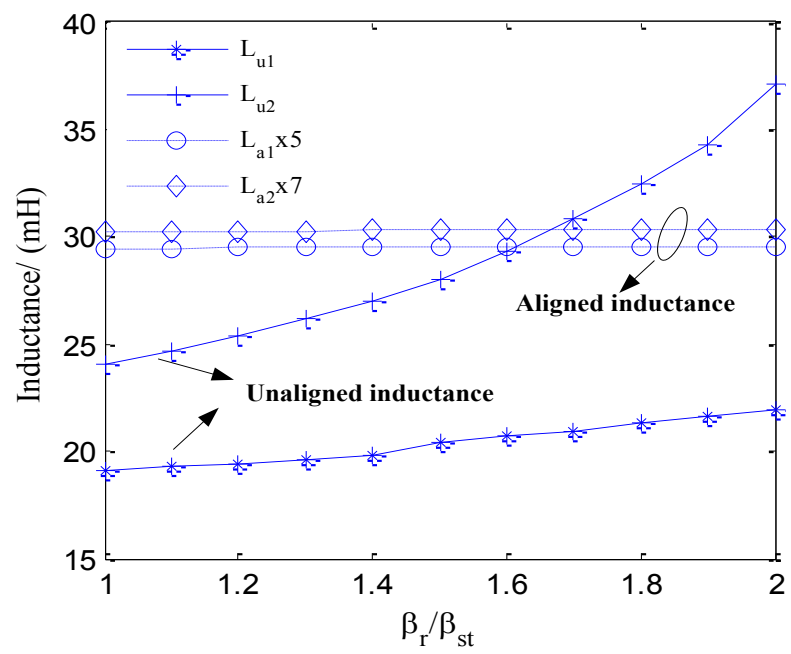

Fig. 7. Sensitivity of inductance vs. rotor to stator pole arc ratio and for various values of stator pole enclosure

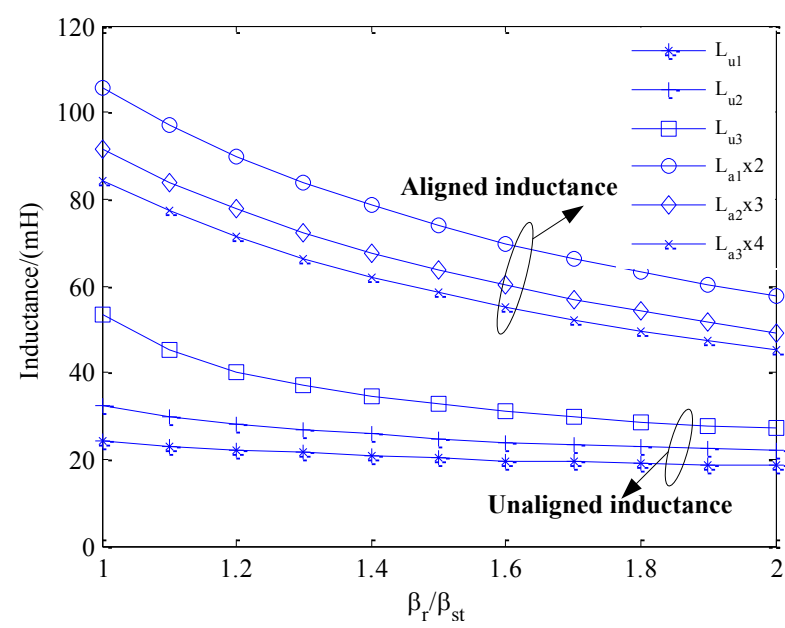

Fig. 8. Sensitivity of inductance vs. rotor to stator pole arc ratio and for various values of rotor pole enclosure 
The guidelines that follow from these observations are that the rotor pole enclosure factor should be in the range of 0.3 to 0.5 , and the stator torque pole enclosure factor in the range of 0.35 to 0.5 . Any further increase in the rotor pole enclosure will result in more iron volume, higher inertia and lower $1^{\text {st }}$ critical speed. A higher value than the recommended value for the stator pole enclosure factor will reduce the space for installing excitation windings and increase stator weight as shown in Fig. 9.

From (14), the stator radial force pole enclosure is only dependant on rotor pole number. The value is equal to one rotor pole pitch. Therefore, if the stator radial force pole enclosure is fixed, the radial force is proportional to the rotor pole arc enclosure factor when other related parameters are fixed. From this view, a higher rotor pole enclosure factor is advantageous for generating higher radial force.

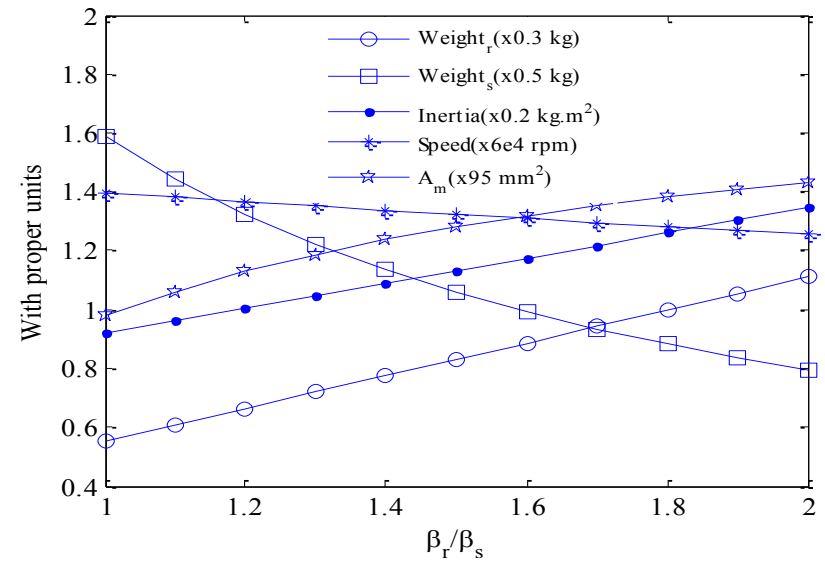

Fig. 9. Plots of weights of motor, inertia, the first critical speed and area for installing windings vs. rotor to stator pole arc ratio

\subsection{Selection of Air-gap Length}

The effect of air-gap length on the electromagnetic torque and radial force is derived in this part. Firstly, a liner magnetic circuit and neglecting fringing effect may be considered. Electromagnetic torque can be derived from (1) and (3):

$$
T=\frac{\mu_{0} W_{s t}^{2} L_{s t k} R}{4 g} i_{s t}^{2}
$$

Combining (4) and (16), it can be observed that torque is inversely proportional to the air-gap length and radial force is inversely squarely proportional to the air-gap length. Thus, any decrease in air-gap results in an increase in the electromagnetic torque and radial force. The reason is that aligned inductance is very sensitive to the air-gap length, and the case for the unaligned inductance is the opposite. Aligned inductance obviously increases with the decrease of air-gap length. Unaligned inductance almost remains constant. The above analysis can be reflected in Fig. 10 .

However, the manufacturing tolerance supported in the production environment is an important factor driving the minimum air-gap length determination. Therefore, air-gap length is selected in the range of $0.25 \mathrm{~mm}$ to $0.5 \mathrm{~mm}$.

\section{Mechanical Consideration}

\subsection{Hoop Stress}

The concentrated stress due to the hole in a plane is called hoop stress. The rotor lamination ring can be treated as a plane sheet having a hole in the middle. The centrifugal forces at high speed cause hoop stress in the rotor yoke. This is a tensile stress, which is tangential to the circumference of the stack ring to resist the strain causing the ring to lift off the shaft as shown in Fig. 11.

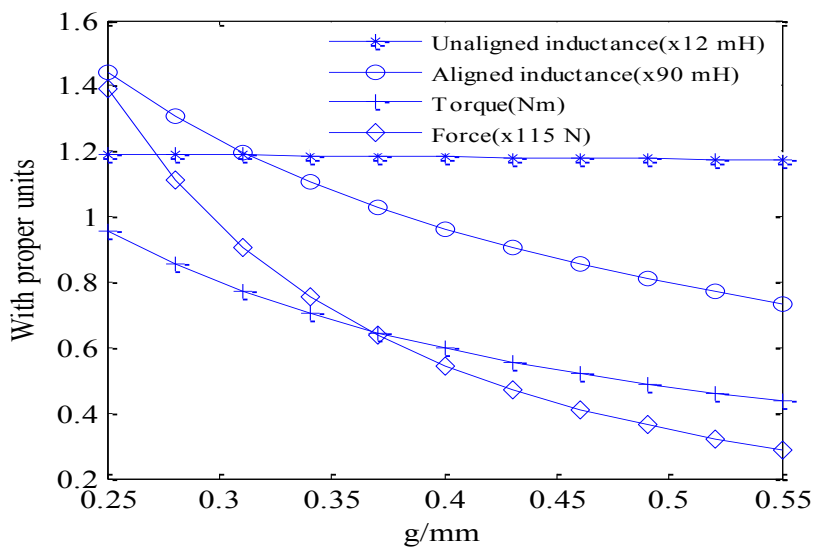

Fig. 10. Plots of inductances, torque and radial force vs. airgap length

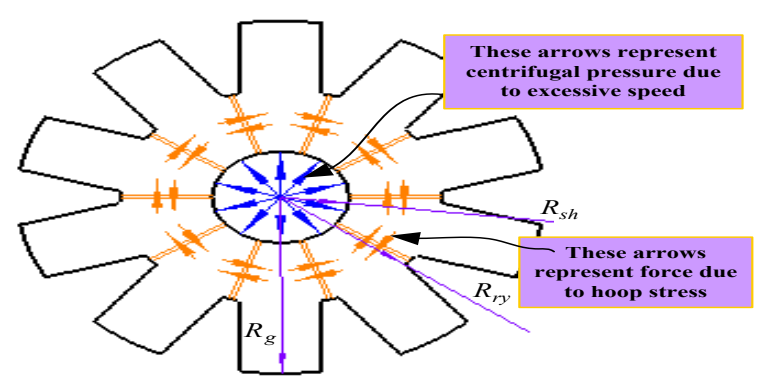

Fig. 11. Rotor lamination ring of the proposed BLSRM showing hoop stress

During the design, it must be assured that the hoop stress generated in the rotor lamination ring is less than the rotor's 
yield strength. A simple calculation is given as follows [78].From Fig. 11, the weight of each sector can be obtained:

$$
M_{\text {rotor }}=\rho_{m} L_{s t k}\left[\frac{\pi \beta_{r}}{180} R_{g}\left(R_{g}-R_{r y}\right)+\frac{\pi}{N_{r}}\left(R_{r y}^{2}-R_{s h}^{2}\right)\right]
$$

where, $\rho_{m}$ is density of rotor material.

Accordingly, the centrifugal load on this section is:

$$
F_{c}=\frac{M_{\text {rotor }} \omega^{2}}{2} R_{\text {mean }}
$$

where, $R_{\text {mean }}$ is the average radial length of the rotor.

Taking into account the directions of these forces, the corresponding stress is this force divided by the yoke section.

$$
P_{h s}=\frac{F_{c}}{2 \cos \left(180 / N_{r}\right)\left(R_{y r}-R_{s h}\right) L_{s t k}}
$$

According to (17) (19), hoop stress is largely determined by the outer radius of rotor $R_{g}$, shaft radius $R_{s h}$ and speed. The effects of these three parameters on hoop stress are shown in Fig. 12. From this figure, hoop stress increases with the increase of $R_{g}, R_{s h}$ and speed. However, the influence of speed on hoop stress is the most noticeable. Therefore, it is possible to design a high speed high power motor by increasing stack length $L_{s t k}$ and decreasing $R_{g}$ for a reduced rotor hoop stress.

\subsection{Critical speed}

The rotor's first critical speed $\omega_{c}$ is higher with a larger shaft radius $R_{\text {shaft }}$, SCR Thyristor Based Three-Phase Voltage Disturbance Generatora lower rotor weight and a smaller stack length. This is because they maximize the lateral stiffness of the rotor [9].

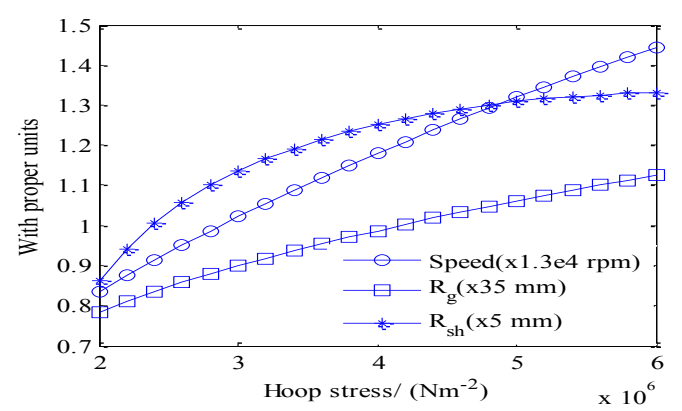

Fig. 12. Plots of speed, outer radius of rotor and shaft radius vs. hoop stress
To avoid mechanical problems, it is important to calculate the shaft diameter carefully. The deflection of the shaft is:

$$
\partial=\frac{F \cdot L_{s t k}^{3}}{6 E \cdot \sigma_{i f}}
$$

$E$ is the elastic module for the shaft. $L_{s t k}$ is the length of the stack. $\sigma_{i f}$ is the surface inertia factor. The rotational force on the shaft $F$ is:

$$
F=m \cdot \partial \cdot \omega_{c}^{2}
$$

Combining (20) and (21), the first critical speed $\omega_{c}$ is:

$$
\begin{gathered}
\omega_{c}=\sqrt{\frac{6 \cdot E \cdot \sigma_{i f}}{m \cdot L_{s t k}}} \\
\sigma_{i f}=\frac{\pi \cdot d^{4}}{64}
\end{gathered}
$$

$m$ and $d$ are mass and diameter of the shaft, respectively. The calculated critical speed should be larger than the rated speed.

According to $(20) \sim(23)$, critical speed is mainly decided by rotor weight, stack length and shaft radius. Generally, when axial length is fixed, rotor weight is dependent on rotor pole arc and outer radius. Fig. 13 shows the first critical speed with the variation of the above parameters. With the increase of the pole arc of the rotor, outer radius, axial length, and critical speed will decrease. However, critical speed will increase with the increase of the shaft radius. Therefore, at the same time as increasing stack length, it is necessary to increase shaft radius to get a tradeoff between hoop stress and critical speed. Also an adequate decrease in rotor pole arc is another way to increase critical speed.

\section{Sizing of Envelope and Internal Dimensions}

\subsection{Design Ratios}

The design ratios are defined to be the ratios between various internal dimensions of the machine. In the selection of design ratios, saliency ratio, unaligned inductance, torque and radial force are taken into account. Referring to Fig. 14, the ratio $\alpha_{h r t r}$ is selected based on the desired saliency ratio and unaligned inductance [10]. 


$$
\alpha_{h_{r} t_{r}}=h_{r} / t_{r}
$$

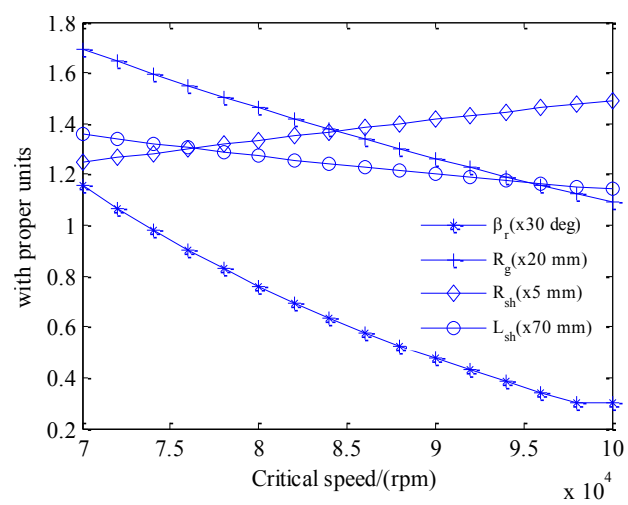

Fig. 13. Plots of pole arc of rotor, outer radius of rotor, shaft radius and axial length vs. the first critical speed

Fig. 14 shows the unaligned inductance with respect to $\alpha_{h r t r}$. From this figure, the unaligned inductance gradually decreases with the increase of this ratio. However, when the ratio value increases to 1.2 , the unaligned inductance almost remains constant. At the same time, the aligned inductance is insensitive to this ratio. Its value changes very little. Therefore, an adequately higher $\alpha_{\text {hrtr }}$ ratio results in a lower unaligned inductance, which generates a higher saliency. Accordingly, the controller Volt-Amp requirement decreases and output torque increases. The objectives for selecting optimal value for other design ratios such as $\alpha_{y s t s}$, $\alpha_{y r t r}, \alpha_{d}$ are minimizing noise, maximizing utilization of material and insuring a mechanical intensity and critical speed well above the rated speed. Table 2 gives a list of these design radios for the BLSRM design.

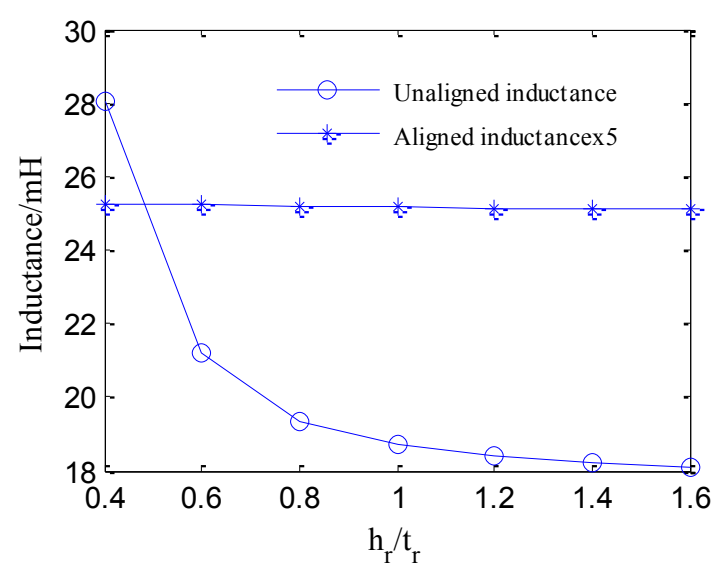

Fig. 14. Plots of inductances vs. rotor pole height to pole width ratio

in which, $\quad \alpha_{y s t s}, \alpha_{y r t r}, \alpha_{d}$ are defined as follows:

$$
\begin{aligned}
& \alpha_{y_{s} t_{s}}=y_{s} / t_{s} \\
& \alpha_{y_{r} t_{r}}=y_{r} / t_{r} \\
& \alpha_{d}=D_{s o} / D_{r o}
\end{aligned}
$$

Table 2. List of Design Ratios for BLSRM

\begin{tabular}{|c|c|c|c|}
\hline$\alpha_{\text {hrtr }}$ & $\alpha_{y s t s}$ & $\alpha_{y r t r}$ & $\alpha_{d}$ \\
\hline $1 \sim 1.4$ & $0.8 \sim 1.2$ & $0.6 \sim 0.7$ & $1.8 \sim 2.1$ \\
\hline
\end{tabular}

\subsection{Sizing of $h_{r}, h_{s}, R_{s h}, t_{r}, t_{s}, y_{s}$ and $y_{r}$}

The basic dimensions of the BLSRM are shown in Fig. 15. Firstly, according to (12), the inner diameter of the stator Dsi can be estimated. So, Rout can be obtained after selecting $\alpha \mathrm{d}$ :

$$
R_{\text {out }}=\left(\frac{D_{s i}}{2}-g\right) \alpha_{d}
$$

Pole widths tr and ts are the lateral length of the rotor and stator pole arcs, respectively. The two values can be achieved after choosing $\beta$ st and $\beta$ r. The yoke thicknesses ys, $\mathrm{yr}$ and rotor pole height $\mathrm{hr}$ can be calculated after choosing design ratios aysts, ayrtr, $\alpha$ hrtr and pole arc enclosures of the stator and rotor. Therefore, shaft radius can be described as follows:

$$
R_{s h}=R_{g}-h_{r}-y_{r}
$$

when $R_{\text {out }}, R_{g}$ and $y_{s}$ are known, $h_{s}$ can be obtained as following equation:

$$
h_{s}=R_{\text {out }}-g-R_{g}-y_{s}
$$

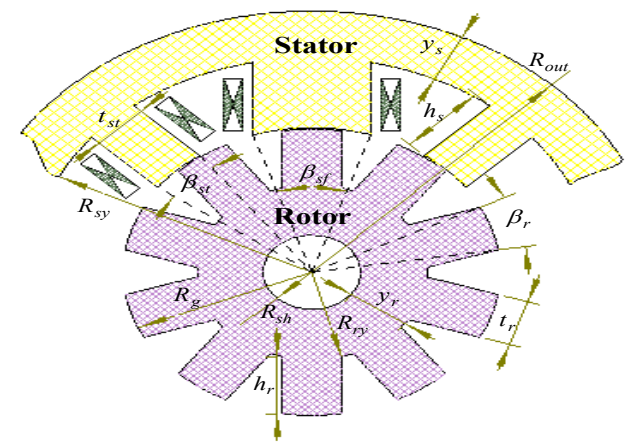

Fig. 15. Basic dimensions description of proposed BLSRM 


\section{Characteristic of Proposed BLSRM}

In this section characteristics of the proposed structure are analyzed, including magnetic flux distribution, inductance, torque and radial force vs. position. Meanwhile in order to verify the advantages of the proposed method, conventional structure is also analyzed.

Fig. 16 shows magnetic flux distribution of torque winding and radial force winding.

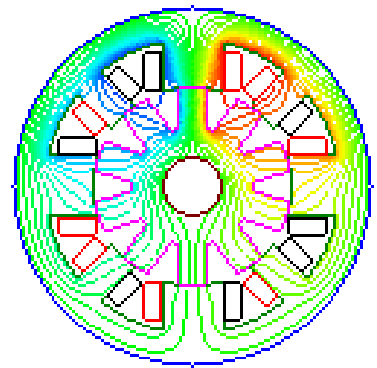

(a)Radial force winding

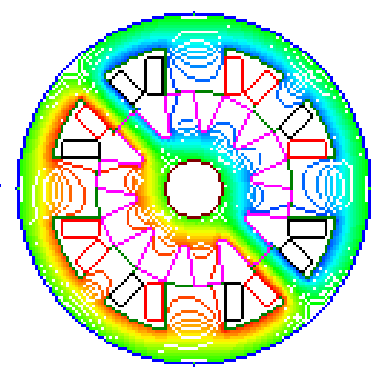

(b) Torque winding
Fig. 16. Magnetic flux distribution of proposed BLSRM

Magnetic flux generated by radial force winding mainly goes through poles of radial force winding. A few numbers of fluxes go through poles of torque windings. However because of symmetric structure, forces on the poles of torque windings are counterbalanced. In Fig. 16(b) the path of magnetic flux is same to that of a conventional SRM.

The torque characteristics are dependent on the relationship between flux-linkage and rotor position as a function of current. The developed torque is proportional to the square of the current and slope of inductance. Fig. 17 shows the inductance profiles for torque winding and radial force winding with various rotor positions and currents, respectively. From Fig. 17 it can be seen that core saturation increases with the increasing of phase current, accordingly maximum inductances of two types of windings decrease. Meanwhile, different from the torque winding, the inductance profile of radial force winding changes very little for different positions with the same phase current. Therefore the generated torques of the two types of windings is shown in Fig. 18. It can be found that torque generated by a radial force winding is very small compared with that of a torque winding. This is because the variation ratio of inductance is very small.

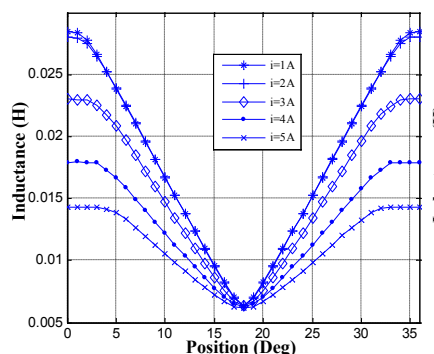

(a) Torque winding

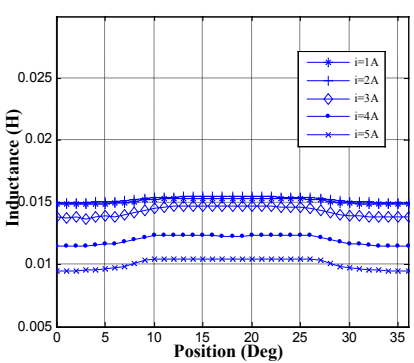

(b) Radial force winding
Fig. 17. Inductance profiles of proposed BLSRM

According to the above analysis, radial force is mainly supplied by a radial force winding. Fig. 19 shows the distribution of radial force with different currents, positions and directions for pole $\mathrm{P}_{\mathrm{x} 4}$ of radial force winding. From Fig. 19 we can find that with the increasing of current, radial forces increase.

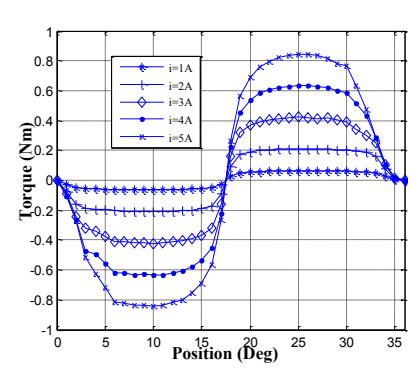

(a) Torque winding

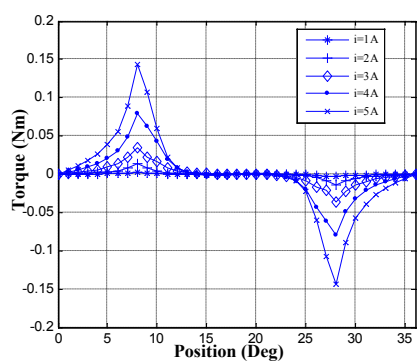

(b) Radial force winding
Fig. 18. Torque profiles of proposed BLSRM

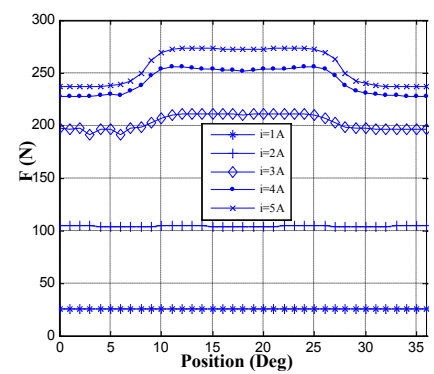

Fig. 19. Radial force profiles of proposed BLSRM

To explain the merits of the proposed structure, a conventional BLSRM is also analyzed. In a conventional structure, currents $i_{\mathrm{ma}}$ and $i_{\mathrm{sa} 1}$ are conducted for generating radial force in the analysis. In the proposed structure, current $i_{1}$ is conducted. The results are shown in Fig. 20. 
From the figure, we can find that radial force in the proposed structure remains almost constant with the variation of rotor position. However in the conventional structure, radial force varies noticeable with rotor position. In order to satisfy higher radial force, the current in the radial force winding of a conventional structure has to be increased.

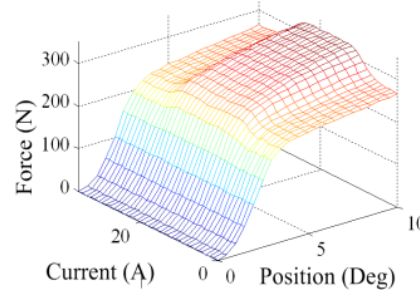

(a) Proposed BLSRM

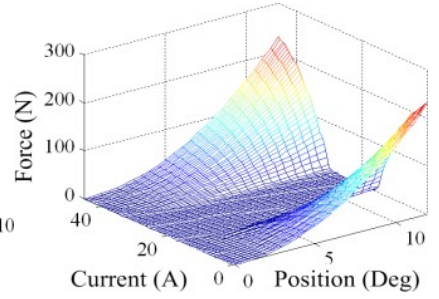

(b) Conventional BLSRM
Fig. 20. Comparison of radial force

\section{Experimental Results}

Experimental verification of the BLSRM with hybrid stator poles was performed to verify its validity. Fig. 21 shows stator and rotor designed for the prototype system. Detailed specifications of proposed BLSRM are shown in Table 3.

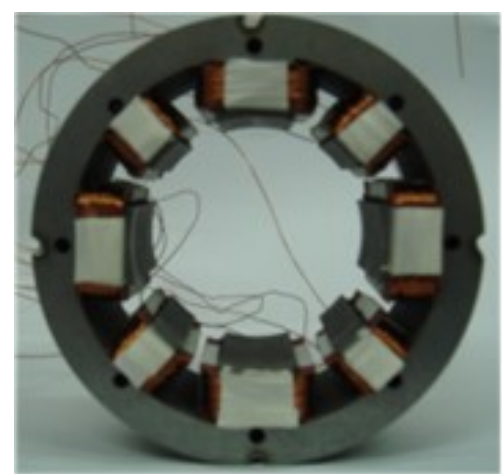

(a) Stator

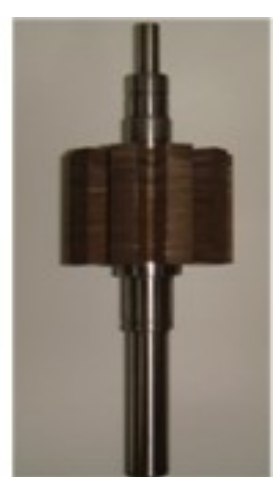

(b) Rotor
Fig. 21. Prototype motor of proposed BLSRM

Table 3. Specifications of Prototype BLSR

\begin{tabular}{|c|c|}
\hline Parameter & Value \\
\hline Number of Stator Poles & 8 \\
\hline Number of Rotor Poles & 10 \\
\hline Pole arc of stator for torque $(\mathrm{deg})$ & 18 \\
\hline Pole arc of stator for radial force $(\mathrm{deg})$ & 36 \\
\hline Pole arc of rotor $(\mathrm{deg})$ & 18 \\
\hline Length of axial stack $(\mathrm{mm})$ & 40 \\
\hline Outer Diameter of Stator $(\mathrm{mm})$ & 112 \\
\hline
\end{tabular}

\begin{tabular}{|c|c|}
\hline Inner Diameter of Stator $(\mathrm{mm})$ & 62 \\
\hline Yoke Thickness of Stator $(\mathrm{mm})$ & 10 \\
\hline Length of Air Gap $(\mathrm{mm})$ & 0.3 \\
\hline Inner Diameter of Rotor $(\mathrm{mm})$ & 18 \\
\hline Yoke Thickness of Rotor $(\mathrm{mm})$ & 9.7 \\
\hline
\end{tabular}

Fig. 22 shows the static experimental result. A $0.6 \mathrm{kgf}$ load is applied in radial directions. The top two curves are displacements in $\mathrm{x}$ and $\mathrm{y}$ directions, respectively. From the result, it can be seen that when the suspending controller is applied, the rotor can be kept in the balanced position.

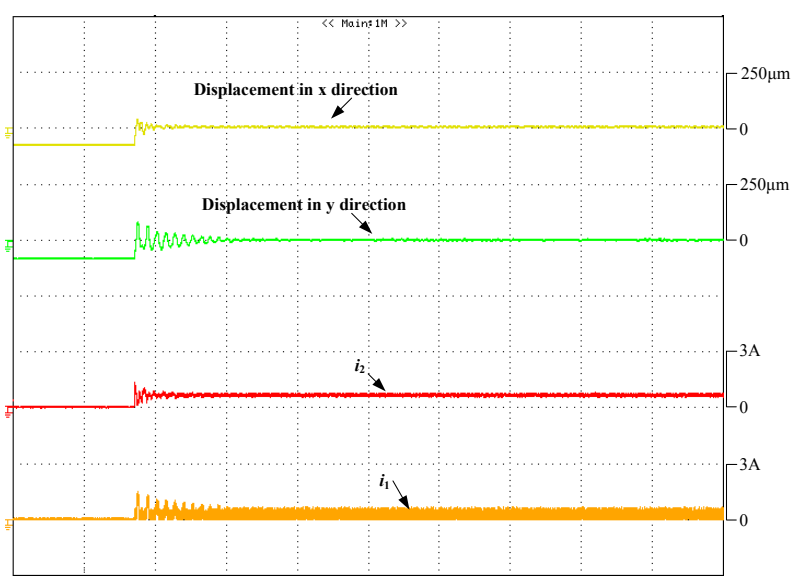

Fig. 22. Static experimental result

\section{Conclusions}

In this paper, a novel structure of BLSRM is proposed. Basic design methodology such as selection of phase number, and pole number is illustrated. The critical issues of mechanical design and radial force are addressed in the design process. Further, characteristic curves including inductance, torque and radial force are obtained. Compared with the conventional structure of a BLSRM, the proposed structure has some advantages, such as lower thermal load, and a simpler control algorithm. The validity of the structure is verified by experimental results.

\section{References}

[1] M. Takemoto, A. Chiba, H. Akagi and T. Fukao, "Radial Force and Torque of a Bearingless Switched Reluctance Motor Operating in a Region of Magnetic Saturation" in Conf. Record IEEE-IAS Annual Meeting, 2002, pp. 35- 42.

[2] Li Chen, Wilfried Hofmann, "Analytically Computing Winding Currents to Generate Torque and Levitation Force of a New Bearingless Switched Reluctance Motor", in Proc.12th EPE-PEMC, Aug, 2006, pp. 1058-1063. 
[3] Carlos R. Morrison. Bearingless Switched Reluctance Motor. U.S. Patent 6,727,618, 2004.

[4] W. T. Liu and S. M. Yang, "Modeling and Control of A Selfbearing Switched Reluctance Motor," in Proc. IEEE IAS Annu. Meeting, Kowloon, HongKong, Oct.2005, pp. 2720 2725 .

[5] Zhan Qionghua, "Switched Reluctance Motors", Huazhong University of Science and Technology, Press, 1992.

[6] J. Faiz and J. W. Finch, "Aspects of design optimization for switched reluctance motors," IEEE Trans. Energy Conversion, vol. 8, pp. 704-713, Dec, 1993.

[7] A. V. Radum, "Design considerations for the switched reluctance motor," IEEE Trans. Ind. Applicat., vol. 31, pp. 1079-1087, Sep./Oct. 1995.

[8] M. N. Anwar, Iqbal Husain, A. V. Radun, " A comprehensive design methodology for switched reluctance machines," IEEE Trans. IAS, vol. 37, pp. 1684-1692, Nov/Dec, 2001

[9] Larsson. M., Johansson. M., Naslund, L., Hylander J, "Design and evaluation of high-speed induction machine," in Conf. IEMDC'03, vol. 1, pp. 77-82, 2003.

[10] T.J.E. Miller, "Switched Reluctance Motors and their Control”, Oxford University Press, 1993

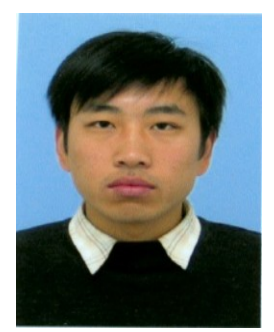

Huijun Wang received his M.S and $\mathrm{Ph} . \mathrm{D}$. degrees in electrical engineering from Shenyang University of Technology and Kyungsung University, in 2006 and 2009, respectively. His research interest is electrical machines and their control.

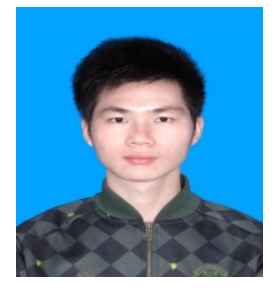

Jianfeng Liu received his B.E degree in electrical engineering from Beijing University of Chemistry and Technology. His research interest is electrical machines and their control.

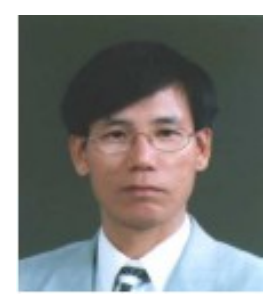

Jin-Woo Ahn was born in Busan, Korea, in 1958. He received his B.S., M.S., and Ph.D. degrees in Electrical Engineering from Pusan National University, Busan, Korea, in 1984, 1986 and 1992, respectively. He has been with Kyungsung University, Busan, Korea, as a professor in the Department of Mechatronics Engineering since 1992. He was a visiting researcher in the Speed Lab at Glasgow University, U.K., a visiting professor in the Dept. of ECE and WEMPEC at the University of Wisconsin-Madison, USA, and a visiting professor in the Dept. of ECEat Virginia Tech from July 2006 to June 2007. He was the director of the Advance
Electric Machinery and Power Electronics Center. He was also the director of the Smart Mechatronics Advanced Research and Training Center from Aug. 2008 to July 2011, and has been the Senior Easy Life Regional Innovation System since July 2008 and president of Korea Regional Innovation System Association since December 2011 which are authorized by the Ministry of Knowledge Economy, Korea. He is the author of five books including SRM, the author of more than 150 papers and holds more than 25 patents. His current research interests are advanced motor drive systems and electric vehicle drives. He is Editor-inChief of JICEMS and associate editor of Journal of Electrical Engineering \& Technology. Dr. Ahn has received several awards including the Best Paper Award from the Korean Institute of Electrical Engineers in 2002 and 2011 The Korean Federation of Science and Technology Society in 2003, Korean Institute of Power Electronics in 2007, Park Min-Ho Prize in 2009, Busan Science \& Technology Prize and Ministerial Citation, Ministry of Knowledge Economy, Korea, in 2011, respectively. He is a fellow member of the Korean Institute of Electrical Engineers, a member of the Korean Institute of Power Electronics and a senior member of the IEEE. 